\title{
Co-existence relationship of residential apartments and furniture in the republic of Korea
}

\author{
Hye-Sung Kang / Min-Soo Kim / Seoul National University / Seoul / Korea
}

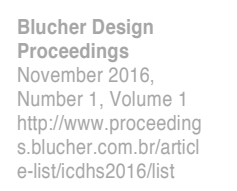

\begin{abstract}
As of the year 2012, more than half the population of the Repblic of Korea (ROK) reside in apartments. Because the majority of the residential properties are comprised of apartments the main target customers for the manufacturers and service providers would naturally be the apartment residents at the early stages of product development. The co-existence relationship between the apartment complexes that multiply themselves by virtue of multiple imitation systems and the products that again repeatedly get imitated to take advantage of this multiplication has to be an interesting topic to explore. This topic would have a close connection with examination of directions of development of the apartments and Korean furniture manufacturing industry to their present states, as well as with examination of the mutual relationship between them.
\end{abstract}

\section{Keywords}

Product standardization, furniture industry, South Korea, apartments

\section{Introduction}

In South Korea, apartments began to be built in the 1930s and they are still the most popular type of housing. This housing type presented in this article differs from those typical in Western Europe, such as the habitations à loyer modéré (HLM). Apartments often signify poverty in major European cities, whereas South Koreans, particularly the bourgeoisie, appreciate this form of collective living. Since the advent of new residential areas, apartments have been built with various architectural appearances featuring different structures, sizes, facilities, and equipment, among others.

In compliance with current building codes in South Korea, the forms of housing generally fall into two categories, namely, detached houses and apartment buildings. The number of the latter has increased constantly by 3\% to $4 \%$ a year since 2000 (Ministry of Land, Infrastructure, and Transport, 2013). The vast majority live in apartments. Six out of ten people in metropolitan areas live in common housing based on 2012 data.

The popularity of this housing type has shifted the target of the furniture industry: toward potential apartment residents. Furniture companies focus on these consumers during the first stage of the development process and then develop products that suit them. The production of uniform apartment products has improved as well. This study focuses on the research problem of product standardization in South Korean apartment standards and market supply, with a specific examination of whether consumers are deprived of opportunities to experience variety in furniture choices in this context.

This article presents an examination of the symbiotic relationship between the replication system of large apartment complexes and reproductive products influenced by this type of housing environment in South Korea. The beginning of the standardization in housing and expansion of such housing phenomenon is observed through the aspects of this mutual relationship and co-evolution.

This symbiotic relationship between the two requires a discussion of the evolutionary process occurring within a sociocultural context. This study analyzes this mutual relationship to examine the effects of housing unification in the process of standardization on our lives, as well as the significance of these effects.

This study focuses on the period between the late 1970s and the mid-1990s. In the 1970s, numerous studies on standardization were carried out in accordance with governmental policies following a large supply of apartments becoming available, which the public in turn became accustomed to as a typical housing type, until the mid-1990s 
when floor plans for apartments became inflexible. Analyses were performed through: reviewing governmental and corporate reports on housing standardization, apartment floor plans, and advertisements in newspapers and magazines, that were published in the selected time period.

\section{Apartments and standardization}

It is crucial to establish standards in industrialized countries, and standardization should be performed in advance of the process of urbanization. In the field of construction, standardization contributes to reduced loss and increased profits in mass production and streamlined use of materials, thereby facilitating the establishment of a reasonable production process. The Netherlands, Japan, and Singapore were among the countries that realized that they needed large-scale housing construction; thus leading to discussions around the standardization-related issues. Problem solving methods for standardization and uniform floor plans were also discussed in countries that have a long history of apartment housing availability.

Studies on housing standardization in South Korea were first carried out during the country's period of industrialization, when housing policies were established and large-scale construction of apartments was undertaken, as part of the initial Five-Year Economic Development Plan of the Korean government in 1962. Standardization of housing and materials was essential for large-scale housing construction. Apartments were the optimal product to provide a large number of houses at low cost in a short period of time (Ministry of Works, 1981). Studies on standardization in this period attempted to apply modules for furniture and material standardization to floor plans of detached houses, row houses, and apartments. These assessments found that only the floor plans of apartments were appropriate for contemporary housing-related policies. Follow-up studies focusing on standardization and apartments were continuously performed until the late 1980s.

The fixation on apartment plan types was also significantly linked to an obsession with economic logic and efficiency in Korean housing standardization. Whereas small apartments used to be irregularly supplied, since the late 1980s, political effects, such as tax benefits and priority decisions for allocating property, have shaped the establishment of the frame of constructing apartments that have areas of $60 \mathrm{~m}^{2}, 85 \mathrm{~m}^{2}, 102 \mathrm{~m}^{2}$, and $135 \mathrm{~m}^{2}$ as standardized space (Cho and Park, 1998). As a result, once consumers had chosen a certain floor space, they had no option but to accommodate themselves to a uniform floor plan, as the number of bedrooms and composition of public space were fixed according to the particular housing size. The method of dividing pre-set unit plans only leads to a limited number of floor plans. Additionally, one study indicated that while different apartment suppliers provide distinct plan types, there are common patterns found between these plan types (Kim and Park, 1992).

Studies on plan classification problematically promoted a uniformity process disguised as standardization. A research report published by the Korea National Housing Corporation in 1988 details a study on the application of system furniture to apartment houses for the effective use of residential space, and argues that a consistent size system should be developed, in terms of creating a relationship between the building frame and furniture to effectively use space by removing dead space in apartment houses.

Setting the module size of system furniture and establishing it as a national standard has the following advantages: First, the quantity of furniture that is carried while moving can be minimized. Second, resource waste can be reduced and economic loss can be minimized by partially replacing parts of the furniture that were damaged while being used, or easily enlarging furniture if necessary. Finally, an increase in the overall quality and durability of furniture could be promoted to enable standardized furniture use in buildings. Despite these benefits, the government's projects on the standardization of system furniture were only focused on apartments. Systematized furniture modules have not been implemented due to various circumstances, including a conflict of interest among furniture manufacturers.

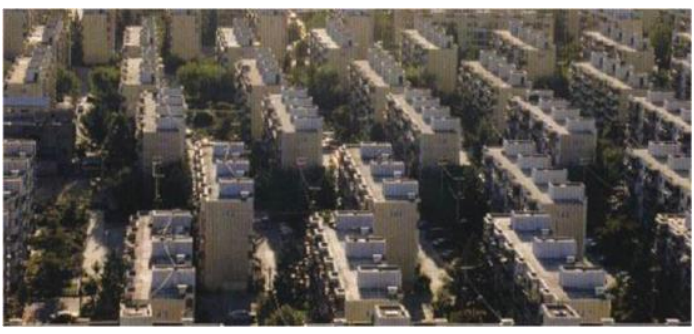

Fig. 1: Jamsil Siyoung apartment 1970 in Seoul

\section{The birth of standardized furniture for apartment}

The capital city, Seoul, saw an unprecedented acceleration toward urbanization due to economic growth. The apartment blocks indicated a real urban development alongside government policies in the 1970s. [figure1] In parallel to the development of apartments, furniture was mass produced in the 1960s. At that time, apartments were popularly seen as a part of the picture of modern life. 


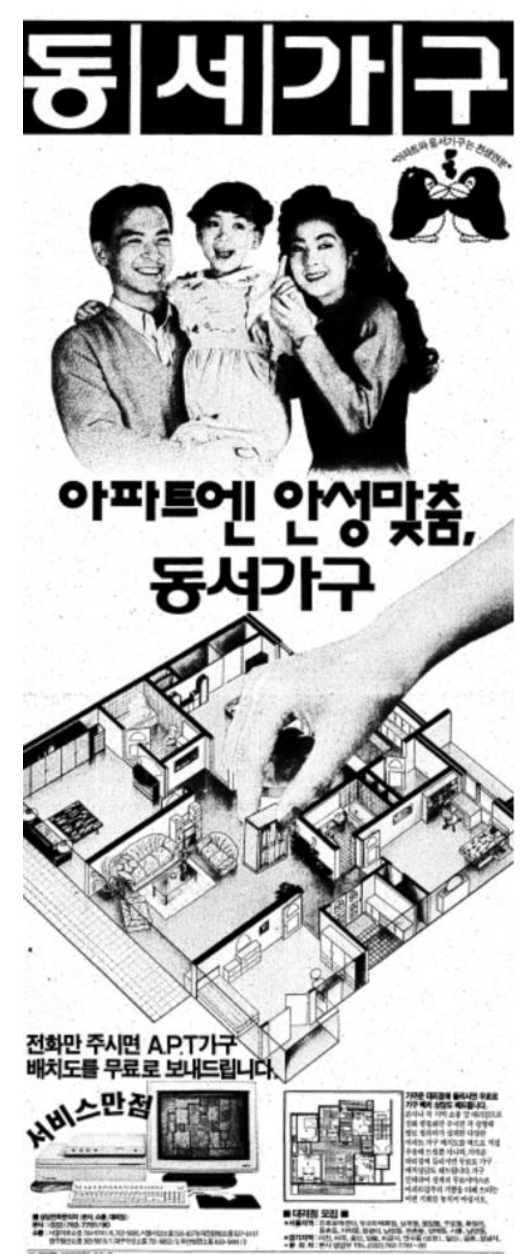

Fig. 2: A furniture advertisement in a Korean newspaper in 1991
Real estate developers featured detailed internal spaces that conformed to modern styles as people demanded for a variety of types of apartment structures. There was also a demand to fill these houses with furniture. In response to this demand, a Korean newspaper advertisement in 1991 targeted the apartment residents using the term "the apartment furniture" (APT Furniture). [figure 2] In this publicity, furniture items are mounted on an apartment akin to Lego blocks to encourage interested customers to purchase a plan designed to fill their houses with furniture via a simple phone call.

The emergence of the new term APT Furniture in this social environment is debatable (Nam Young-lak, 2001). The concept began to appear in reference to furniture designed specifically for the apartment plan. Since the 1980s, apartments have been considered as an investment rather than a place of residence. Many apartments located in the Gangnam district in Seoul showed an increase in prices close to 14 times than its price 10 years ago. People dreamed of climbing the social ladder through the acquisition of apartments. Their dreams became reality easily because to the expansion of apartment constructions. When the price of the apartment increases sufficiently after a few years of purchase, people upgrade their apartment in search for a higher profit.

As this purchasing behavior developed, people invested less in home interior products. People do not spend money for a place they consider leaving soon because they are already thinking of the new apartment's decoration, which they have not moved into yet. They choose to abandon their existing furniture from their former apartment to ensure the harmonious interior of their new apartment. Further efforts to harmonize incongruous furniture products require money and time. Meanwhile, it is also necessary to consider the ease of mobility in the future. This new behavior is spreading among city dwellers rapidly as it is difficult and often unattractive to reorganize an apartment by combining new furniture with the old ones.

The culture of consumption referred to as the "Furniture Packages," where built-in furniture match the wallpaper, began to emerge in the new apartments. [figure 3] The furniture manufacturing industry is threatened in South Korea, but furniture distribution companies remain successful. Those "Made in China," synonymous with poor quality, were intended to be discarded after a period of use. Nonetheless, they fully meet society's expectations. Indeed, under capitalism, furniture also joined the tragic fate of other products: that of being thrown into landfills after they are no longer deemed useful.

\section{Who are "non-standard customers"?}

The market size of the Korean domestic furnishing was about KRW 9 trillion in 2011(Statistics Korea, 2011). Furniture imports represented nearly KRW 1.2 trillion or $12 \%$ of the total amount. The proportion of the Korean brand market was KRW 4.3 trillion or $52 \%$ of the total KRW 8.2 trillion. The figures show that the furniture consumption in South Korea responds to the domestic market demand. More than half of the Korean furniture purchases represented items manufactured by large national companies even while, in 2008, statistics showed that small and medium enterprises (SMEs) accounted for the majority of the market share of the furniture industry. This trend indicated the scale of influence of major brand companies in the Korean furniture market.

In this unfavorable environment, most SMEs tend to imitate the existing products of major brand companies rather than invest in product research. This inclination has led to problems of scarcity as regards diversity in models, design, or sizes in the furniture market. Thus, consumers' choice has become considerably limited when buying furniture products in Korea.

In the 1970s, brand furniture items were produced to correspond to the demands for apartments. As apartments were recognized as modern Western-style houses, new wardrobe designs began to appear and were recommended by specialists in magazines as a way of embracing modernity (Housing, Vol.9 No.1, 1968). This period thus formed the desire for new furniture to blend in the newly built civilization that obliges living in an 
apartment. [figure 4]

Before discussing the present day "non standard customer", a review of the history of furniture is necessary; this review includes the history of wardrobe, which is the most important furniture in traditional culture and has undergone the most visible change in Korea. The introduction of the apartment as a housing type triggered the use of built-in wardrobes to maximize storage space and enable greater ease in moving. The built-in wardrobe was a valuable alternative that addressed the lack of storage space, which was the biggest problem in living in an apartment compared with traditional houses. In the 1960s, the South Korean furniture industry grew rapidly along with the increase in the necessity of organizing wardrobes containing Western clothes.

The new form of built-in wardrobe replaced the traditional one (janglong) as apartments grew in popularity. Janglong's symbolic character in one's marriage and as traditionally the most important piece of furniture in a couple's life faded.

The universal diffusion of fixed furniture is relatively recent; fixed furniture represented only $2 \%$ of the total installations since 1998. Since the 2000s, the market for built-in furniture, particularly the wardrobe, expanded due to the increase in the reconstruction and renovation of apartments. Major brand companies, which had been sensitive to the needs of their customers, responded to the demands for apartment residents and then the SMEs reacted in turn. According to South Korea's current codes of construction, the minimum ceiling height for a building is $2,400 \mathrm{~mm}$. As the average height of the apartments built in the last years measured between 2,300 and $2,400 \mathrm{~mm}$, the wardrobe furniture market had also grown to maximize its storage function according to the recommended standard. Consequently, it has been difficult to find built-in wardrobes below 2,200 mm in height among furniture brands in the domestic market.

During the 1980s, apartments with low ceiling became popular with the development of New Towns because lowering the ceiling maximizes the developers' profits. The minimum ceiling height was only 1,800 $\mathrm{mm}$ until 1999, before reforms in the law were made.(Choi Seng-gil, 1999) The difference between the height of the furniture, especially the wardrobe, and ceiling ended in a discord among furniture manufacturers whether to standardize their mass production for new or old apartment residents or non-residents of apartments. In this study, these consumers are called non-standard customers.

The non-standard customers refer to the people who live in a type of housing in which a mass-produced fixed furniture could not be installed. They are residents of apartments and detached houses with a ceiling height under $2,300 \mathrm{~mm}$ and over $3,000 \mathrm{~mm}$, respectively. As such, their only solution is to buy customized products that are more expensive. Their choice when purchasing furniture is also limited.

Many written accounts of these non-standard customers are presented in the Web and online interior design communities. However, these complaints are insignificant in a society where three quarters of more than 45 million people live in apartments. The core issue is not only about the cost or limited options of wardrobe furniture but the synthesis of these comments with regards to their effect on daily lives and society.

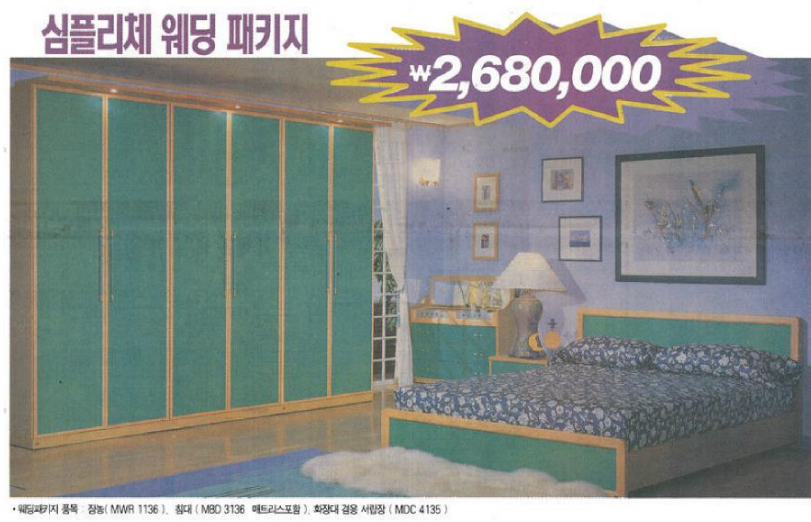

Fig. 3: A furniture advertisement "Wedding Packages" in a Korean magazine in 1995

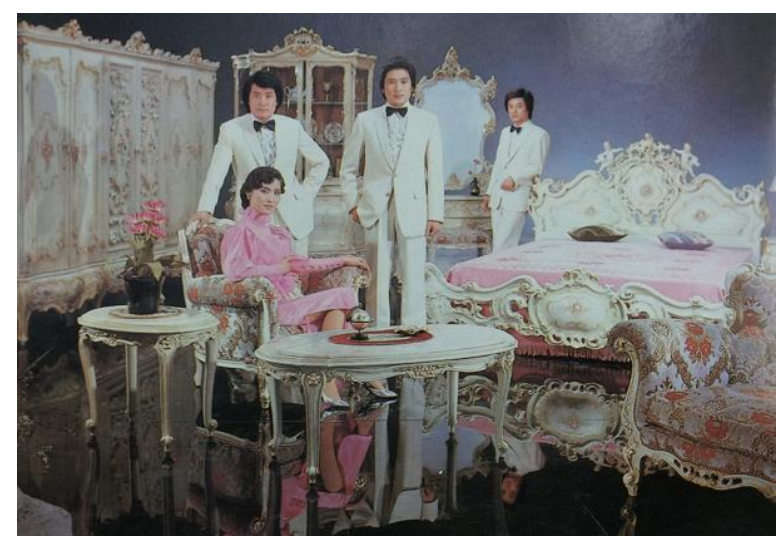

Fig. 4: A furniture advertisement in a Korean magazine in 1984

\section{Conclusion}

This article attempts to elucidate the standardization of housing and furniture problem and the relationship that has transformed the Korean culture. Criteria for standardization are necessary in this age of mass production. The need to standardize required a production reference so that the apartment could become a typical housing type in South 
Korea. The apartment preference could be attributed to the transformation of the societal preference and the rapid eoncomic development, which greatly influenced the culture of consumption.

With this change, there is a societal fear and psychological pressure to not lag behind new treads and lead a similar life to avoid alienation. Decorating the apartment is often a deliberate attempt or an undue impulsive act to prove that one is as good as the others. The perspective of non-standard customers in this context demonstrates the disqualification of disunion in a system of a society. This marginalization leads them to follow the footsteps of those before them for integration into the mainstream.

The uniformity of the unit plan characteristics for the apartments propelled the loss of diversity in furniture. This lack of diversity in the furniture industry has made Koreans' lives standardized. In addition, this problem of uniformity sheds light on the endemic problem of the domestic furniture industry. As the furniture industry has shifted its focus more on the distribution development than the investment in research and development and technical advancement of the furniture design, their inherent competitiveness has gradually weakened.

Rows of apartment complexes continue to thrive in Korea. A similar landscape unfolds across the country. Why do Korean cities look like an army on the march? The proliferation of mass-produced furniture for standardization evidently corresponds to the replication process of the apartment blocks. A scrutiny of the evolution of this mutual association is important for explaining the culture of consumption in Korea. The transformation for progress necessitates an insightful contemplation of the individual and the society.

\section{References}

Cho Sung hee \& Park Su bin (1998). A Study on the Users Need for Developing Diverse Dwelling Unit Plans of Apartment, Architectural Institute of Korea, Architectural Research, 14(11), pp. 153-164.

Choi Seng-gil (1999). Story height of High-rise Apartment Influenced the Life Environment of a Tenant, 産業科學論文集, Vol.7 No.2.

Kim Su-am \& Park Yong-hwan (1992). Inflexeible Pattern of Apartment

Ministry of Works. (1981). A Study on the Standards for Dimension Systems of housing and Housing Performance for Industrialization of Housing Construction.

Nam Young-lak. (2001). A study on the Usability of the Apartment Furniture.

Types and Plans. Review of Architecture and Building Science 27(1), pp. 3-15.

Unit Plan. Architectural Institute of Korea, Architectural Research, 8(7), pp. 73-82.

Yoon et al. (1983). A Study on Housing Standards for Various House

\section{Biographical note}

Hyesung Kang, DD. Candidate, Design History and Culture, Seoul National University. Received DNSEP from Haute école des arts du Rhin in France.

Min-Soo Kim, Professor and Director of Design History and Cultural Studies, graduate course of Seoul National University(www.snu-dhc.com); Received Ph.D from New York University in USA.; Former chief editor of The Journal of Design Culture and Criticism (JDCC, 1999 2002), the first journal of cultural history, theory and criticism on design in Korea. 